\title{
Performance Optimization of Brushless DC Motors Mitigating Voltage Dips, Swells and Short Interruptions in Weak Grids
}

\author{
Hilmy Awad $^{1^{*}}$ and M. M. Gouda ${ }^{2}$ \\ ${ }^{I}$ Electrical Technology, Faculty of Technology and Industrial Education, Helwan University \\ ${ }^{2}$ Electronics Technology, Faculty of Technology and Industrial Education, Helwan University \\ *Corresponding Author: hilmy_awad@yahoo.com
}

\begin{abstract}
Normally, BLDC motor drives a sensitive load which is severely influenced by disturbances such as voltage dips, swells, and short interruptions in weak grids. The main objective of this work is to investigate the performance of BLDC motors when they are tied to weak grids. Thus, this paper presents a study on the performance of BLDC motor considering disturbed utility conditions. Also, an efficient solution to guarantee a soft operation of a BLDC motor driving a sensitive load is presented. A buckboost DC converter is merged with the BLDC drive inverter to be able to mitigate voltage dips as well as voltage swells. A short interruption of one or two phases of the grid voltage can also be mitigated.

The BLDC motor is controlled via a cascade PI-controller layout that has an outer loop for the speed control and inner loop for the DC voltage control. The PI controllers' gains are optimized by using the ant-colony optimization technique and then implemented in a simulation model using MATLAB/SIMULINK. Six cases of disturbances have been simulated including balanced and unbalanced dips, swells, and short interruption of one or two phases of the grid. Simulation results with various disturbances show the ability of the proposed controller to mitigate the grid disturbances with good transient and steady-state responses.
\end{abstract}

Keywords: Ant Colony Optimization; BLDC; Buck-Boost Converter; Voltage Dip; Voltage Swell

\section{Introduction}

Brushless DC (BLDC) motors offer several advantages compared to conventional DC and AC motors. Among those, improved accuracy, reduced maintenance, and energy costs are the most obvious ones [1-4]. Therefore, BLDC motors are exploited in many industrial applications such as hybrid electric vehicles [5-7], air conditioners [8], electric oil pumps [9], wireless medical applications [10], and refrigeration systems [11]. In residential applications, BLDC motor has been designed and tested for mixer-grinder [12] and fans [13].

While BLDC motors can be found as single, two, and three-phase machines, the three-phase motor is the most popular, and its applications are numerous [14]. The stator winding of the three-phase motor is either trapezoidal or sinusoidal. The name trapezoidal or sinusoidal refers to the shape of the back electromotive force that is directly proportional to the speed of rotation. Permanent magnets replace the field windings of the rotor and can be either surface-mounted, embedded or inserted in the rotor.

An electronic switch circuit is utilized to replace the mechanical commutator of brush DC motor. To accomplish the required control performance of the motor speed, the BLDC motor is equipped with a rotor position detector and an inverter bridge circuit [15]. Compared to distinctive assortments of motors, BLDC motor embraces the shape of square wave excitation, that improves the utilizing rate of the permanent magnet material, reduces the size of the motor, increases the output power of the motor, and has the attributes of high efficiency and response. As the ratings of the motor increase, the supply is normally provided via a single-phase (low/medium power) or a three-phase uncontrolled rectifier (high power), as depicted in Figure (1).

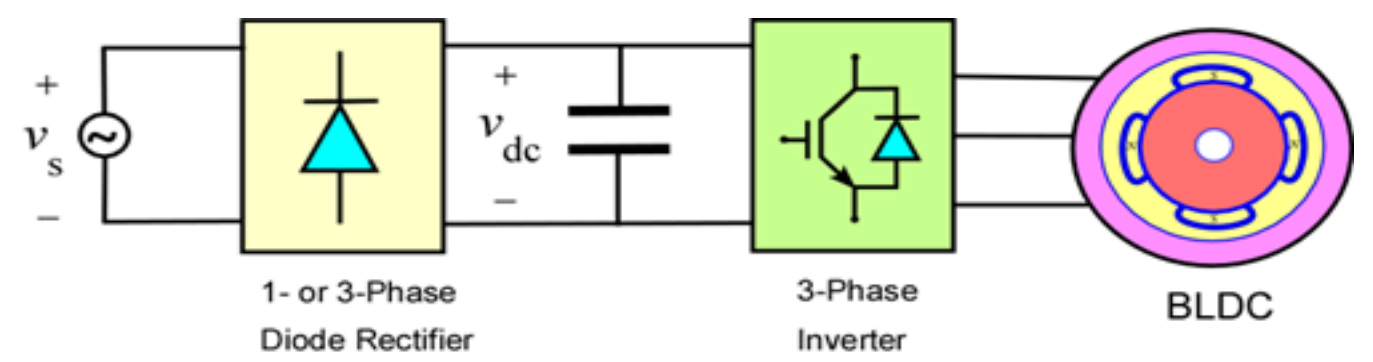

Figure 1-. A BLDC motor fed via a single-phase or three-phase diode rectifiers 
Essentially, control methods are permanently applied to the control of the BLDC motor to improve its performance in terms of torque ripple suppression, rotational speed dynamics, and steadystate response [16-18]. The use of Proportional Integral Derivative (PI)-based controllers on process control has increased due to its reliability and simple structure. However, adjusting PI parameters is not an easy task. In recent years there have been various methods for tuning PI parameters [19]. In a simple application, the trial-error tuning method is used to adjust the PI parameters, but for this method, it is difficult to get the optimal value so that it is difficult to adjust parameters, and it takes a long time, and also the accuracy of the control is not good [20]. In recent years, researchers have used many artificial intelligent methods to determine the PI parameters of BLDC Motor included the PI controller depends on fuzzy rules, the PI controller depends on the neural network, and also the fuzzy PI controller [21]. Then researchers began to study the intelligent behaviour of animals and applied it to be applied to solve optimization problems, especially in the field of control. These animals include bees, ants, wasps, and find a behavioural algorithm from the habits or behaviour of these animals. This includes genetic algorithmic, huge bang-big crunch improvement, artificial bee colony, particle swarm optimization, bacterial foraging, and flower pollination [20, 2236].

Ant-Colony Optimization (ACO) is included in the swarm intelligence group, which is one type of development paradigm used to solve optimization problems where inspiration used to solve these problems comes from the behavior of swarms or swarms of insects. This algorithm was proposed by Dorigo and colleagues [37,38]. Every ant in the herd that is walking will leave pheromone (a kind of chemical) in the path through it. Pheromone is a kind of signal to fellow ants. The shorter path will leave a stronger signal. The next ant, when deciding which path to choose, will usually tend to choose to follow the path with the strongest signal, so that the shortest path will be found because more ants will pass that path. The more ants that pass a path, the stronger signal in that lane. The use of the ACO method is also used in this study as a method for tuning PI parameters.

The effectiveness of whatever control algorithm is normally tested against possible operational disturbances in the motor environment. Operational disturbances include loading variations, external environmental issues such as temperature and pressure, and utility disturbances. Utility disturbances imply input voltage and frequency fluctuations due to unavoidable events during the grid operations such as short-circuit faults, switching on/off large loads, and lightning. The main aim of this paper is to investigate the operation and control of BLDC motor under disturbed utility conditions, where the incoming voltage could have many disturbances or powerquality issues. Section II of the paper presents a brief description of the most common grid disturbances that might highly influence the motor drives. In Section III, the proposed controller and its tuning algorithm are detailed. Simulation results with six cases of disturbances in the grid voltage are presented in Section IV.

\section{Common Grid Disturbances}

As the input power of the motor is taken via a diode rectifier, the dc voltage fluctuates with the grid disturbances (such voltage dips and swells) and hence the motor output (speed/torque) will consequently fluctuate. Hence, a buck-boost converter is implemented, as displayed in Figure (2), to guarantee proper operation and satisfactory performance, albeit most of the common grid disturbances.

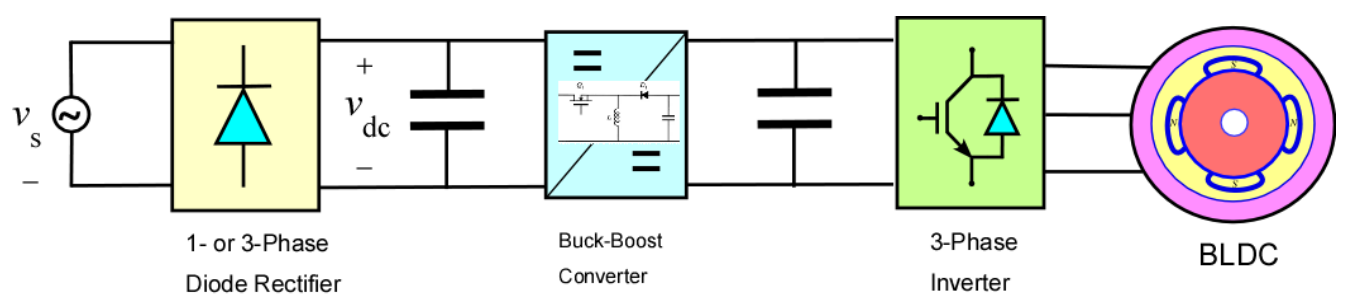

Figure 2- A BLDC motor fed via a single-phase or three-phase diode rectifiers and a buck-boost converter

Due to unavoidable events such as faults and equipment failures, the grid voltage may experience a variety of disturbances such as voltage dips, swells, short interruptions, transients, and harmonics. Such disturbances influence the operation of load equipment and deteriorate the performance. In this work, the focus is given to dips, swells, and short interruptions as they are the most common and severe disturbances.
Severe voltage dips cause the motor drive to trip $[39,40,41]$ and consequently, the associated process will be stopped. In many industrial processes such as chemical processes, the stoppage may cause significant economic issues as it might require a considerable repair that takes a long time [42]. Voltage swells may cause failure and damage to the motor- drive components due to the increase of electrical and thermal stresses [43]. The highest 
thermal stresses on the motor are obtained in the case of short interruption of the supply [44]. Serious consequences of short interruption include tripping or malfunction of protection equipment, loss of data and failure of data processing equipment, tripping of sensitive equipment, such as adjustable speed drives (including the BLDC), programmable-logic controllers.A voltage dip is a decrease in the load voltage below $90 \%$ and above $10 \%$ of the rated value that lasts for less than 1 minute and more than half a cycle [39-41]. Voltage dips are characterized by magnitude, duration, and associated phase-angle jump. Figure (3-a) displays an example of a $70 \%$ voltage dip. Depending on the voltage dip magnitude and duration, the stability of synchronous and induction motors may not be guaranteed, and shut down the operation would be the best choice, scarifying the economic consequences [42]. On the other hand, a voltage swell is an increase of the load voltage below $160 \%$ and above $110 \%$ of the rated value that lasts for less than 1 minute and more than half a cycle [44-48]. An example of a 130\% voltage swell is depicted in Figure (3-b). Voltage swells are not as common as voltage dips, but their consequences are more pronounced.
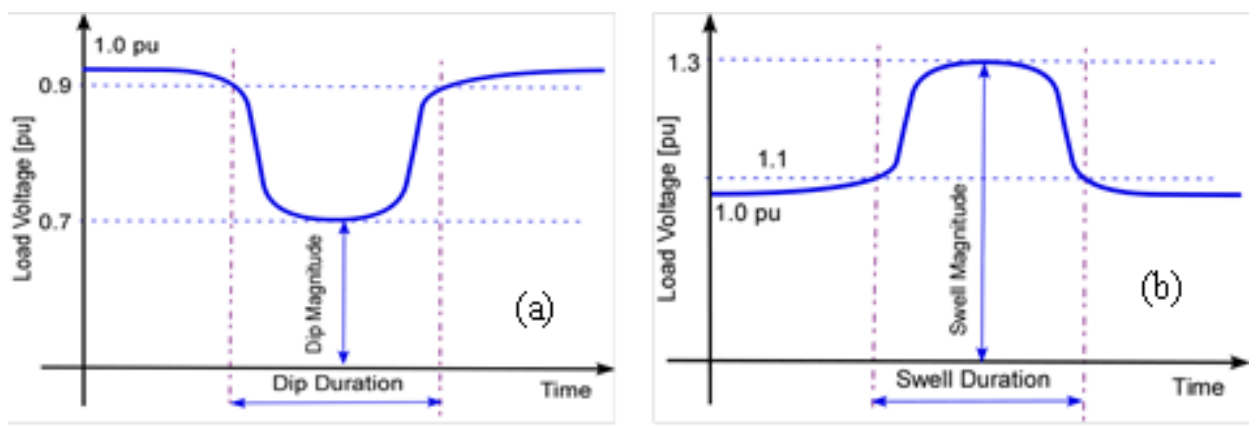

Figure 3- (a) $70 \%$ voltage dip and (b) $130 \%$ voltage swell

In principle, a voltage swell implies an excess of energy coming to the load and must be quickly absorbed. Otherwise, it would damage the sensitive equipment, or at best, the protection system would trip the whole plant.

A short interruption is defined as the loss of power so that the utility voltage goes below $10 \%$ of its nominal value for less than 3 minutes, according to the European standard EN-50160 [47] and 2 minutes according to the standard IEEE-1250. The main reasons for short interruptions are the operation of the automatic reclosers in power systems and equipment failure.

\section{Proposed Tuning Technique of the PI Controller}

\section{A. Ant Colony Optimization (ACO) Technique}

Normally, in automatic control, the optimization process consists of finding the optimum value of the controller parameters so that a closed-loop system consisting of an ant-based PI controller and an unknown plant can minimize or optimize a given cost function. The objective of the proposed controller is to minimize the actual closed-loop specification such as maximum overshoot $\left(M_{p}\right)$, rise time $\left(t_{r}\right)$, settling time $\left(t_{s}\right)$, and steady-state error $\left(\mathrm{e}_{\mathrm{ss}}\right)$. The effectiveness of the proposed controller is quantified by the weighted goal achievement method as a performance criterion, which uses the actual closed-loop specification of the controller system: $M_{p}, t_{r}, t_{s}$, and $e_{s s}$ to evaluate the fitness function. This is done by summing the squares of the errors between actual and specified specifications as shown below [53].

$$
J=\frac{1}{\left[c_{1}\left(t_{r}-t_{r d}\right)+c_{2}\left(M_{p}-M_{p d}\right)+c_{1}\left(t_{s}-t_{s d}\right)+c_{1}\left(e_{s s}-e_{s s d}\right)\right]}
$$

$\mathrm{c}_{1}: \mathrm{c}_{4}$ are positive constants (weighting factor), their values are chosen according to prioritizing their importance, $t_{r d}$ is the desired rise time, $M_{p d}$ is the desired maximum overshoot, $t_{s d}$ is the desired settling, time, and $\mathrm{e}_{\mathrm{ssd}}$ is the desired steady-state error.

In the ACO algorithm, computational resources are allocated to a collection of artificial ants that exploit an environmentally mediated form of indirect communication to find the shortest route from the ant nest to the destination set $[50,51]$. The natural metaphor which is based on ant algorithms is that of ant colonies. Real ants can find the shortest path from a food source to their nest, without using pheromone information by using visual indications. Ants emit pheromone on the ground when walking and are likely to follow pheromone previously deposited by other ants. The ant chooses a route that will pass from point $r$ to point $s$ on a journey with probability:

$p(r, s)=\frac{\gamma(r, s)}{\sum \gamma(r, 1)} s, 1 \in N_{r}^{k}$

matrix $\gamma(\mathrm{r}, \mathrm{s})$ represents the amount of pheromone intensity between points $r$ and $s$. Then the pheromone will be updated via the following equation: 
$\gamma(r, s)=\alpha \cdot \gamma(r, s)+\Delta y^{k}(r, s)$

where $\alpha$ with an interval of $0<\alpha<1$ is power hold a pheromone, then $(1-\alpha)$ represent the evaporation that occurs in pheromones and $\Delta \gamma \mathrm{k}(\mathrm{r}, \mathrm{s})$ is the number of pheromones that ants drop on the route $(\mathrm{r}, \mathrm{s})$.

Pheromone trail (r, s) for the best trips which ants have done (ants that produce optimal parameters PI) will be updated using the following equation:

$\gamma(r, s)=\alpha \cdot \gamma(r, s)+\frac{Q}{f_{\text {best }}} r, s \in J_{\text {best }}^{k}$

where $\mathrm{Q}$ is a positive constant which is a very large value. To prevent stagnation (a situation where ants will follow the same route, which is where will get the same solution), then trace strength of Pheromone is limited at the following intervals:

$\gamma(r, s)= \begin{cases}\tau_{\min } \text { if } \gamma(r, s) \leq \tau_{\text {min }} \\ \tau_{\text {max }} \text { if } \gamma(r, s) \geq \tau_{\text {max }}\end{cases}$

The upper and lower limits are as follows:

$\tau_{\text {max }}=\frac{1}{\alpha . f_{\text {best }}}$

$\tau_{\min }=\frac{\tau_{\max }}{M^{2}}$

where $\mathrm{M}$ is the number of ants that do travel. The solution of the ant colony's journey in optimization PI parameters are plotted into a graph until the maximum limit of iterations. Travel with the best solutions from the ant colony (optimal parameters of PI) for each iteration is plotted to the maximum iteration limit. Flowchart of the Ant Colony method Optimization used to look for parameters the optimal PI is shown in Figure (4) [52].

\section{B. The Implemented Controller of The BLDC Motor}

The implemented controller consists of two loops: an outer speed controller and an inner dc voltage controller. The outer speed controller compares the desired speed $N_{\mathrm{r}}{ }^{*}$ to the actual rotor speed $N_{\mathrm{r}}$ and consequently, an error signal is generated. This error signal is processed by the PI controller to generate the DC reference voltage, which is the input to the inner-loop controller. The inner-loop controller estimates the required duty cycle of the buck-boost converter based on the difference between the reference and the actual values of the dc output voltage. An illustrative diagram of the system and controllers is shown in Figure 5

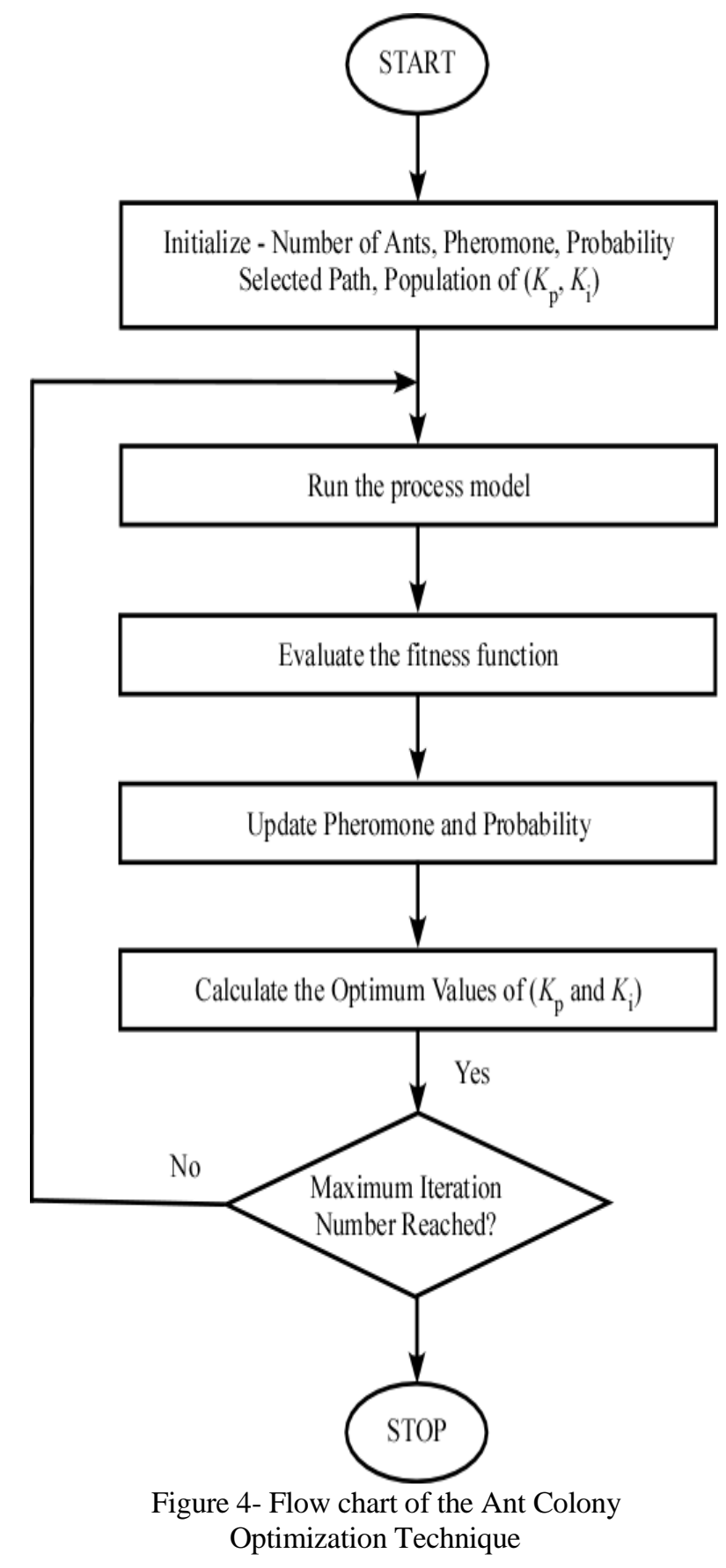

\section{Simulation Results}

A BLDC model (that is built-in MATLAB/ SIMULINK) has been used to verify the efficacy of the controllers and investigate the motor operation under the disturbed utility conditions. The AntColony Algorithm has been implemented to tune 4 controllers gains: $K_{\mathrm{PN}}, K_{\mathrm{IN}}$ for outer-loop controllers and $K_{\mathrm{Pdc}}, K_{\mathrm{Idc}}$ for the inner-loop controllers. 


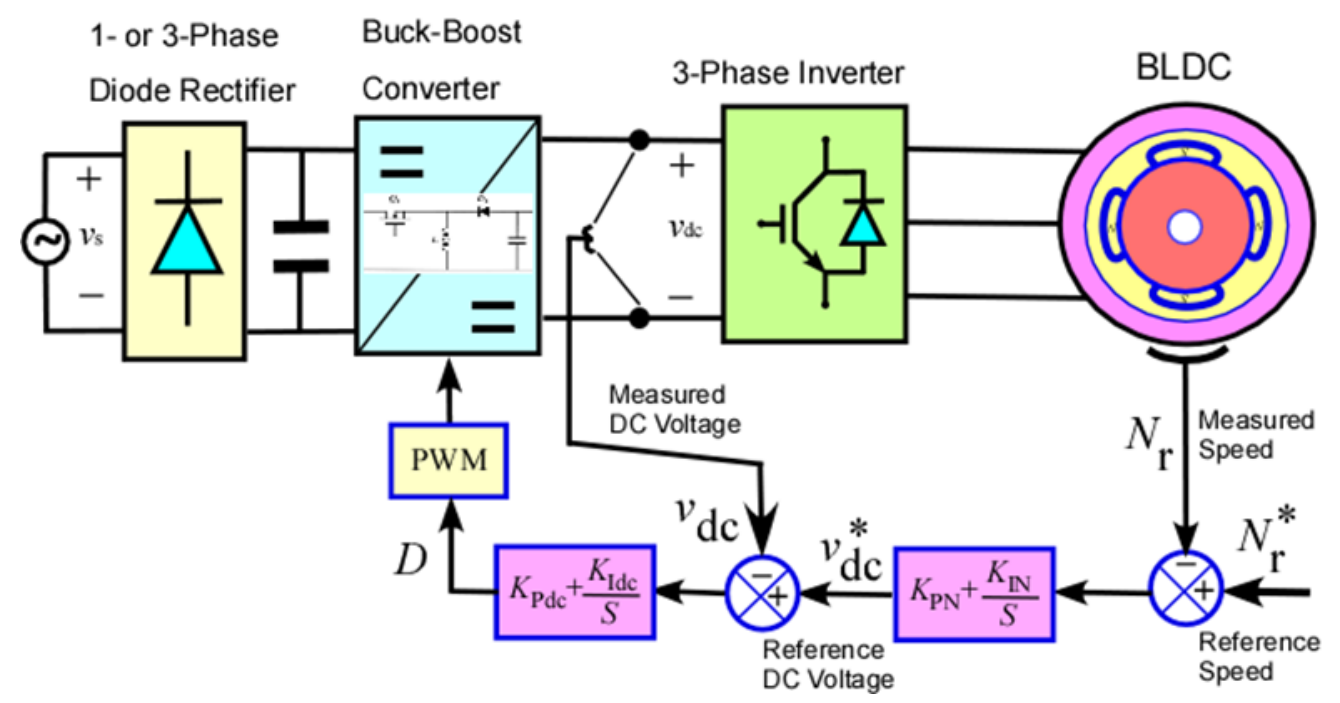

Figure 5- BLDC with two-loop control

The parameters of the Ant-Colony Algorithms are: No. of ants $=100$, initial value of pheromone $=$ 0.06 , evaporation parameter $=0.95$, positive and negative pheromones are $0.2,0.3$, respectively. The PI parameters were obtained using $\mathrm{ACO}$ at the general operating point. It is therefore not essential to achieve new values for these parameters. In particular, there are slight differences between the other operating points. This results in the gains to be: $K_{P N}=0.787, \mathrm{KIN}=117.58, \mathrm{~K}_{\mathrm{Pdc}}=0.935, \mathrm{~K}_{\mathrm{Idc}}=$ 229.09. Then, the simulation model has been implemented with the above gains using SIMULINK. To generate voltage dips, swells, and interruptions, a programmable supply was modeled and incorporated in the simulations. The parameters of the BLDC motor are given in the Appendix.

\section{A. Case 1: $70 \%$ Balanced Voltage Dip}

The most common dip type is the unbalanced voltage dip, while three-phase balanced voltage dips do not occur frequently. However, the case of a balanced voltage dip is investigated here as it is the most severe case for such a system because the controller and the DC converter would need to compensate for a considerable amount of power during the dip. In this case, the supply voltage dips to $70 \%$ of its nominal value for a duration of $0.5 \mathrm{~s}$ (25 cycles) as displayed in Figure (6-a). Consequently, the rectified voltage also drops from 500 to almost $350 \mathrm{~V}$ (70 \% as well) as shown in Figure (6-b). The dc input voltage of the inverter tends to decrease as a response to the dip of the supply, but the controller responds and restores it to its nominal value within approximately $40 \mathrm{~ms}$ as depicted in Figure (6-c). This behaviour is pronounced by the increase in the duty cycle of the Buck-Boost switch from 0.5 to roughly 0.6 as shown in Figure (6-d). The speed response is illustrated in Figure (6-e) where the controller has been able to keep the speed at its nominal value within $50 \mathrm{~ms}$ with a $9 \%$ undershoot and $8 \%$ overshoot at the start and the end of the dip, respectively. In order to compensate for the voltage dip, the controller forces the supply current to increase from 25 to $36 \mathrm{~A}$ as displayed in Figure (6f) during the dip. It is important to clarify that the developed torque of the motor was kept unchanged as depicted in Figure (6-g) because the controller has responded relatively quickly and accurately restoring to the motor voltage to its nominal value.

\section{B. Case 2: $60 \%$ Balanced Voltage Dip}

A more severe case is studied here and again it is not a common one. The grid voltage is decreased from 220 to $132 \mathrm{~V}$ as shown in Figure (7-a) and the rectified voltage consequently decreases to $300 \mathrm{~V}$ during the dip as illustrated in Figure (7-b). Figure (7-c) illustrates that the output voltage of the DC converter is kept constant during the dip and the controller successfully restored it to the nominal value by increasing the duty cycle $8 \%$, compared to the $70 \%$-dip Case as displayed in Figure (7-d). The speed of the BLDC motor is unchanged, albeit the severity of the dip as shown in Figure (7-e). This is manifested in the longer time it takes to settle down which is $80 \mathrm{~ms}$ in this case, compared to $50 \mathrm{~ms}$ in the case of $70 \%$ dip. As the dip is more severe, the DC converter must draw more current and this is depicted in Figure (7-f) where the current raised to $45 \mathrm{~A}$. More importantly, the DC converter control was able to keep a constant-power operation of the BLDC motor as displayed in Figure (7-g) and hence protected the motor against under voltages. 
Hilmy Awad and M. M. Gouda "Performance Optimization of Brushless DC Motors ......."
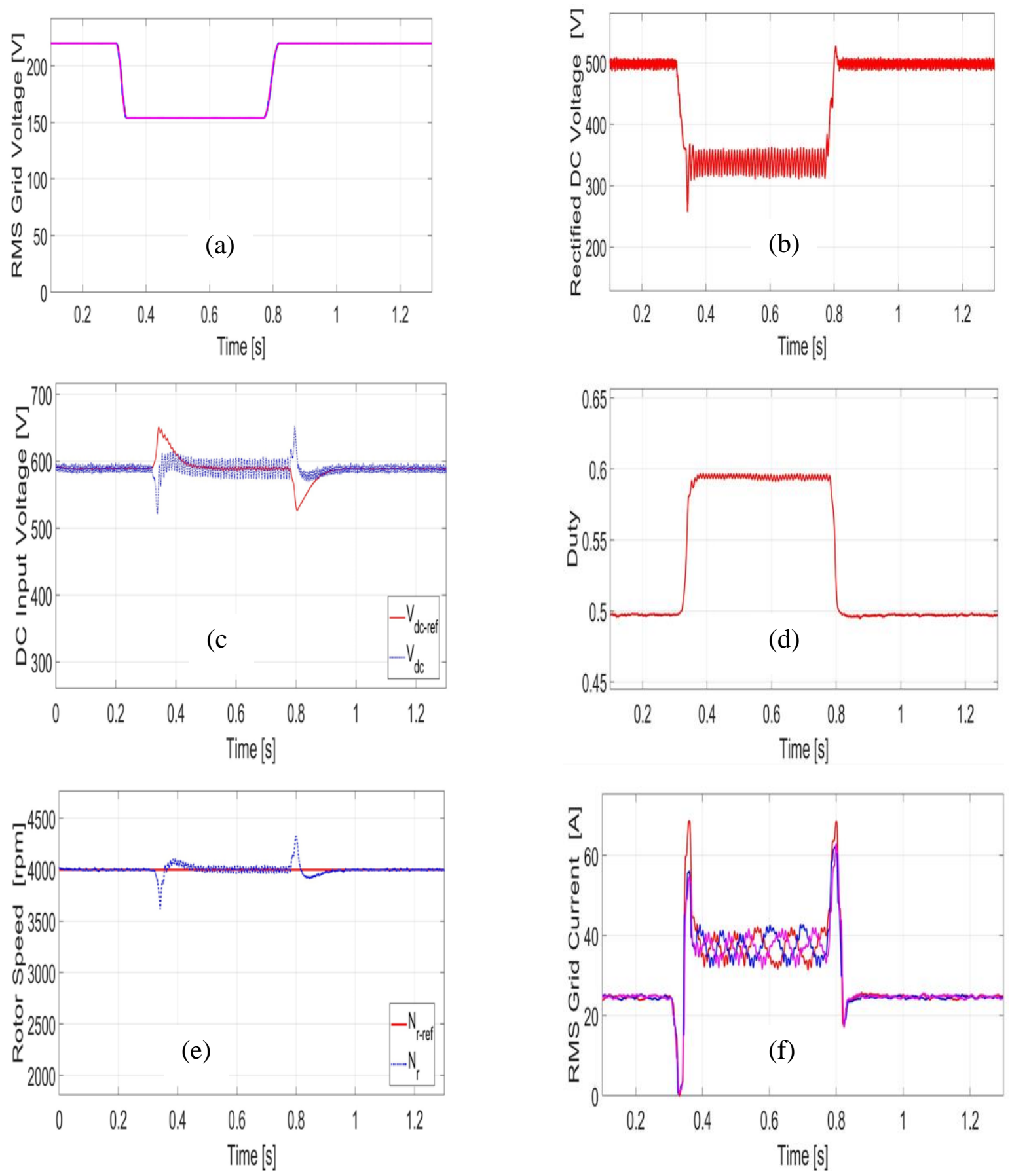

Figure 6- Performance of the BLDC motor in the case of $70 \%$ balanced voltage dip for a duration of $0.5 \mathrm{~s}$; a: Grid Voltage, b: Rectified Voltage, c: Input Voltage of Inverter, d: Duty Cycle of DC Converter, e: Motor Speed, f: Grid Current, and g: Motor Torque

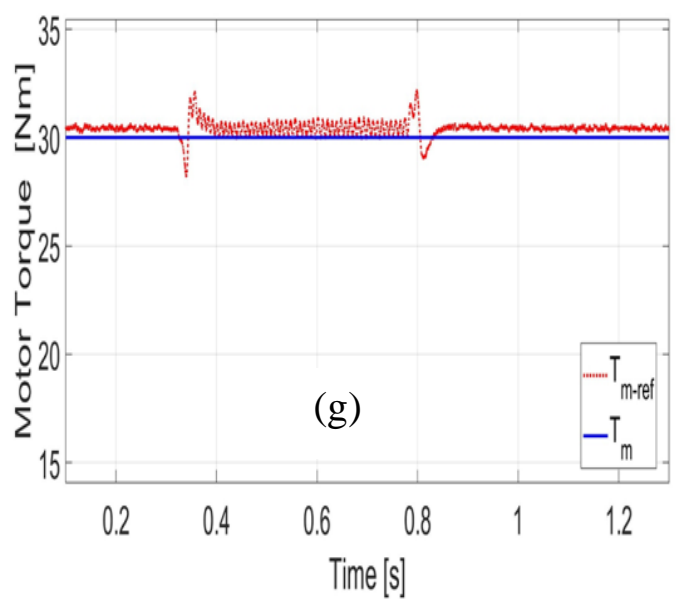



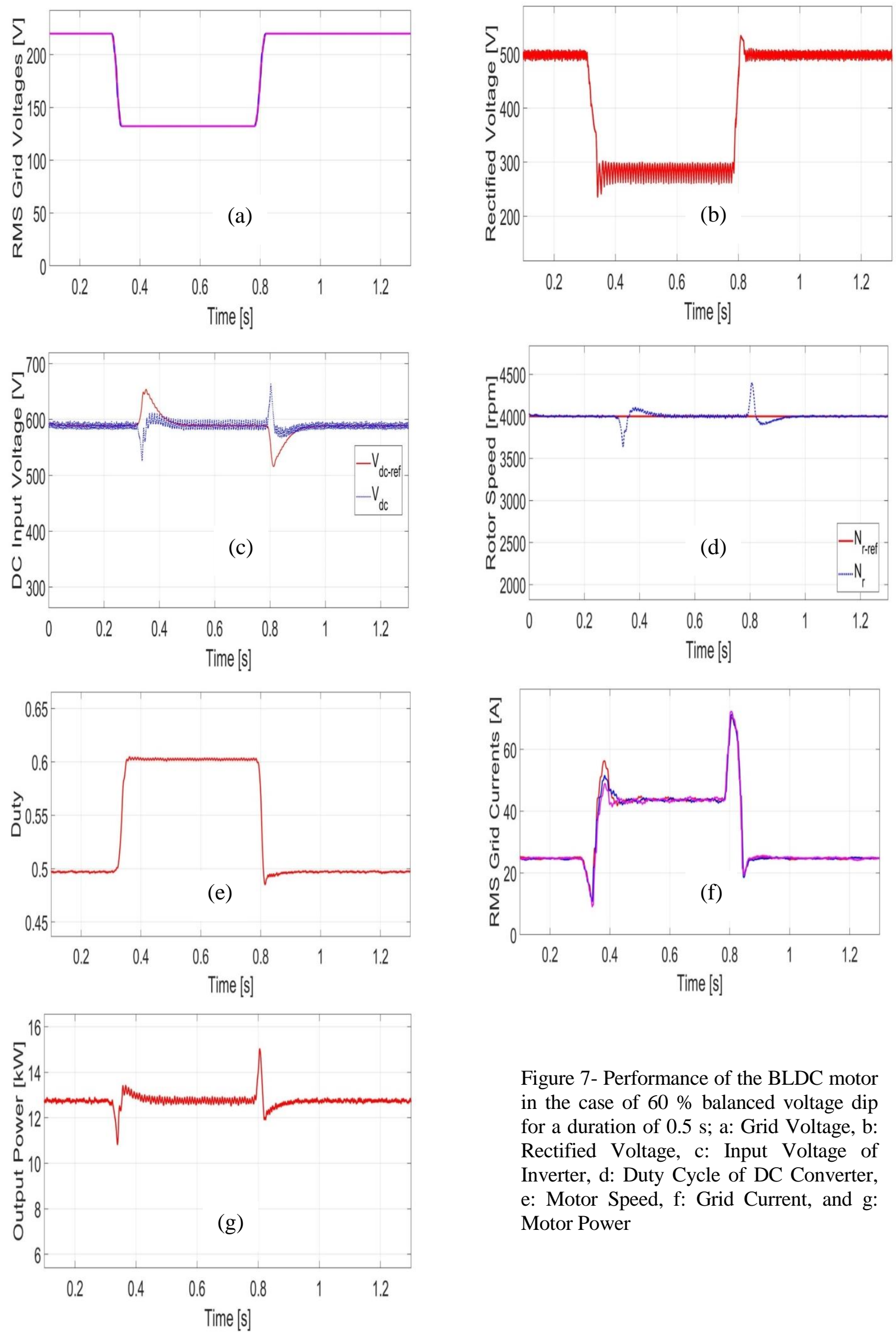

Figure 7- Performance of the BLDC motor in the case of $60 \%$ balanced voltage dip for a duration of $0.5 \mathrm{~s}$; a: Grid Voltage, b: Rectified Voltage, c: Input Voltage of Inverter, d: Duty Cycle of DC Converter, e: Motor Speed, f: Grid Current, and g: Motor Power 


\section{Case 3: 130\% Balanced Voltage Swell}

In this case, the grid voltage is increased to $286 \mathrm{~V}$ (1.3 pu) as depicted in Figure (8-a). A voltage swell may occur due to a capacitor-bank energizing at the grid side and it lasts till the grid voltage regulator restore it back to the nominal value. Here the duration of the swell is $0.5 \mathrm{~s}$ ( 25 cycles).

Due to the voltage swell, the rectified voltage has also increased almost to $1.3 \mathrm{pu}$ as well as displayed in Figure (8-b). Responding to the swell, the dc output voltage of the buck-boost converter tends to increase but the controller was proven to restore it within $40 \mathrm{~ms}$ as shown in Figure (8-c). This was realized by decreasing the duty cycle to from 0.5 to 0.4 as displayed in Figure (8-d). Consequently, the speed of the BLDC motor was controlled and kept unchanged at its nominal value, Figure $(8-e)$. The input current of the converter must decrease, Figure (8-f) to keep the motor constant as illustrated in Figure (8-g).

\section{Case 4: Unbalanced Voltage Dip 90, 70, and 50 $\%$}

Unbalanced voltage dips are more common and mainly occur due to single-phase or double phase to ground short-circuit faults. In this case, the grid voltages are subjected to an unbalanced dip with phases a, b, and c drop to 90, 70, and $50 \%$, respectively as illustrated in Figure (9-a). In response to the grid-voltage unbalance, the rectified voltage drops to an average value of roughly $66 \%$ with a ripple magnitude of $10 \%$ as depicted in Figure (9-b). Such ripples are reflected in the output DC voltage but with less magnitude (6 \%). However, the controller was able to compensate for the dip as displayed in Figure (9-c).

The duty cycle has increased from 0.5 to 0.58 to compensate for the motor as shown in Figure (9-d). There are some ripples in the motor speed as well due to the unbalance as shown in Figure (9-e), but they are small and may not influence the motor operation significantly. Figure (9-f) illustrates that the input current has increased but with different magnitudes as the phases have different voltage magnitudes. The motor power of the motor is compensated but with some little ripples as displayed in Figure (9-g).

\section{E. Case 5: Short interruption of one pha.se of the grid voltage}

In the case of a single line to ground fault at the grid side, normally one phase is completely lost, and its voltage drops to zero until the fault is cleared. This is known as a short interruption. Here, this case is simulated, and the grid voltages are shown in Figure (10-a). Therefore, the rectified voltage is reduced to about $80 \%$ as depicted in
Figure (10-b) but the output voltage of the DC converter is maintained at its nominal value as shown in Figure (10-c) by increasing the duty cycle as represented in Figure (10-d). The motor speed is unaffected by the phase lost as the controller successfully keeps it at its nominal value, Figure (10-e). The currents of the healthy phases have increased, Figure (10-f), to compensate for the power lost during the dip as depicted in Figure (10g).

\section{F. Case 6: Short interruption of two phases of the grid voltage}

An extreme case is assumed here just to test the performance of the controller. That is two phases are completely lost due to a double phase to ground fault as depicted in Figure (11). The performance of the controller is like case 5 as shown in Figure (11) but at the expense of a high value of the grid currents and a longer settling time (60-ms).

\section{Discussions}

The adopted solution is capable of mitigating voltage dips, swells, and short interruptions. However, depending on the sensitivity of the driven load of the motor and the severity of the local disturbances where the motor is installed, more options might be visible. One option could be oversizing the dc-link capacitor and in this case, there is no need for a buck-boost converter. Of course, this is a good solution, but it will not work for variable speed operation. Other options could be the use of a controlled rectifier, either single-phase or a three-phase. For instance, using a PWM rectifier would have more advantages other than controlled input dc voltage, which includes improving the supply power factor and minimizing the supply current distortion. On the other hand, it is worth noting that using the adopted buck-boost converter might reduce the power factor at supply terminals as well as increase the supply current distortion. However, as the duration of voltage dips, swells and short interruption are in the range of 0.5 cycles to less than a minute, the adopted solution will not significantly influence either the supply power factor or the supply current distortion. If any of the two factors is an issue, the buck-boost converter can be operated only if an event is detected. Otherwise, it is bypassed using a thyristor crowbar, for instance. In general, the choice of a particular solution is not an easy task and it will require conducting a feasibility study taking into account all the above-mentioned factors in addition to the total cost of the system. 

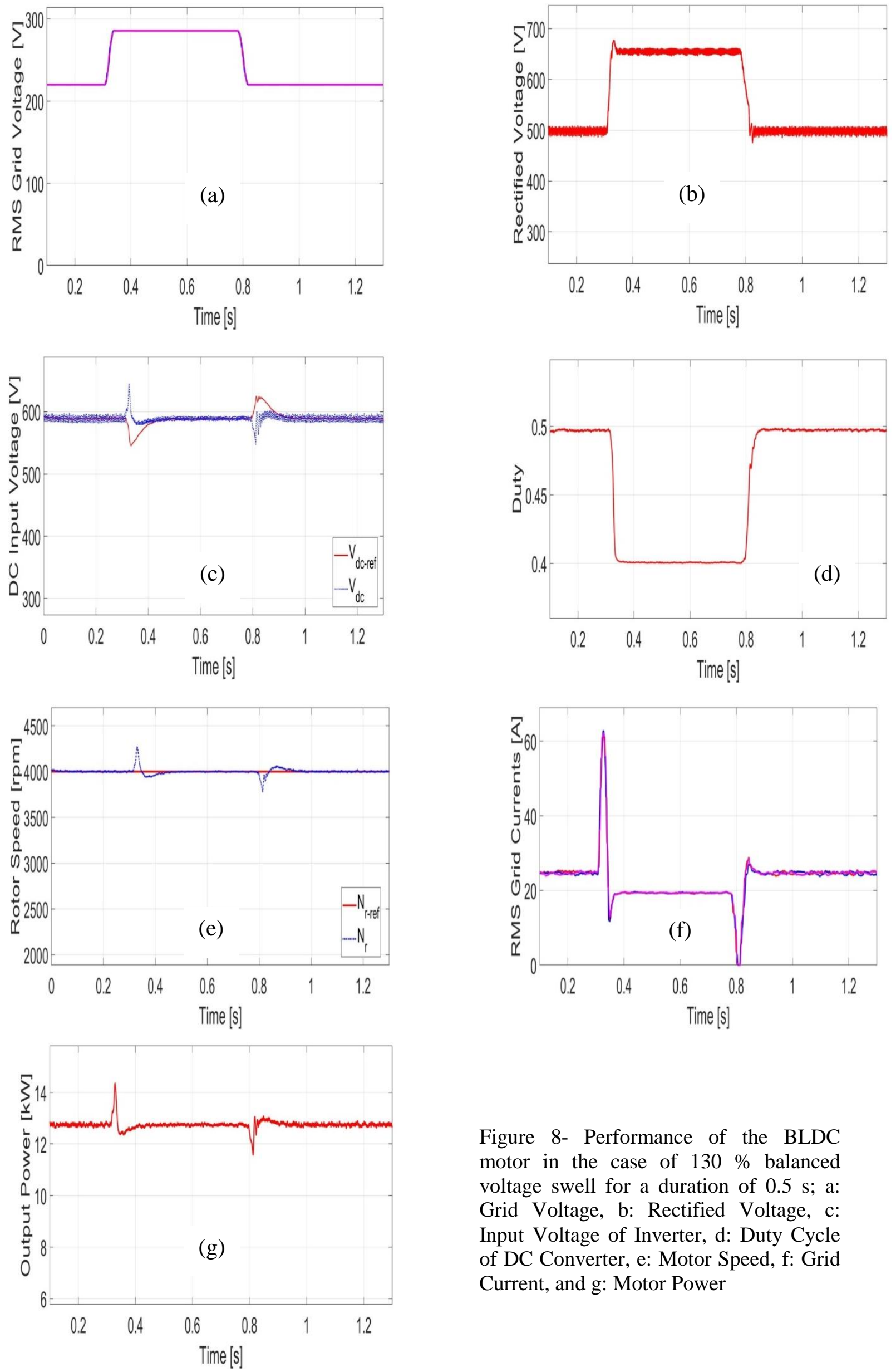

ERJ, Menoufia University, Vol. 43, No. 3, July 2020 

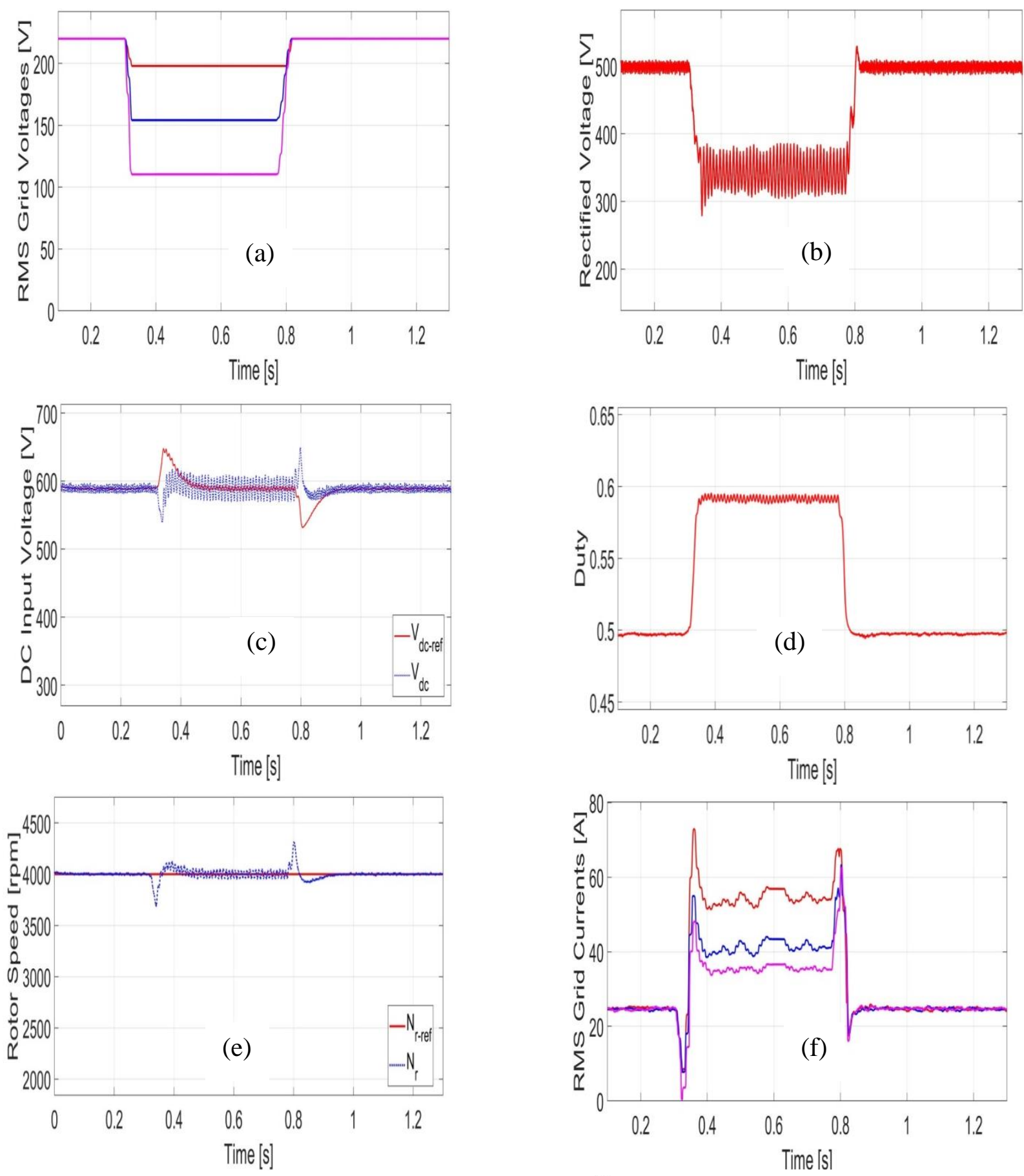

Figure 9- Performance of the BLDC motor in the case of unbalanced voltage dip with magnitudes: 90, 70 and $50 \%$ for a duration of $0.5 \mathrm{~s}$; a: Grid Voltage, b: Rectified Voltage, c: Input Voltage of Inverter, d: Duty Cycle of DC Converter, e: Motor Speed, f: Grid Current, and g: Motor Power

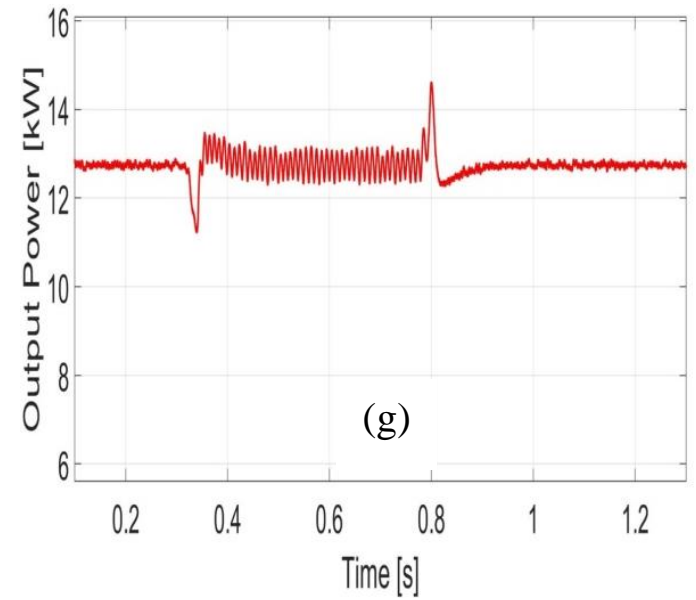



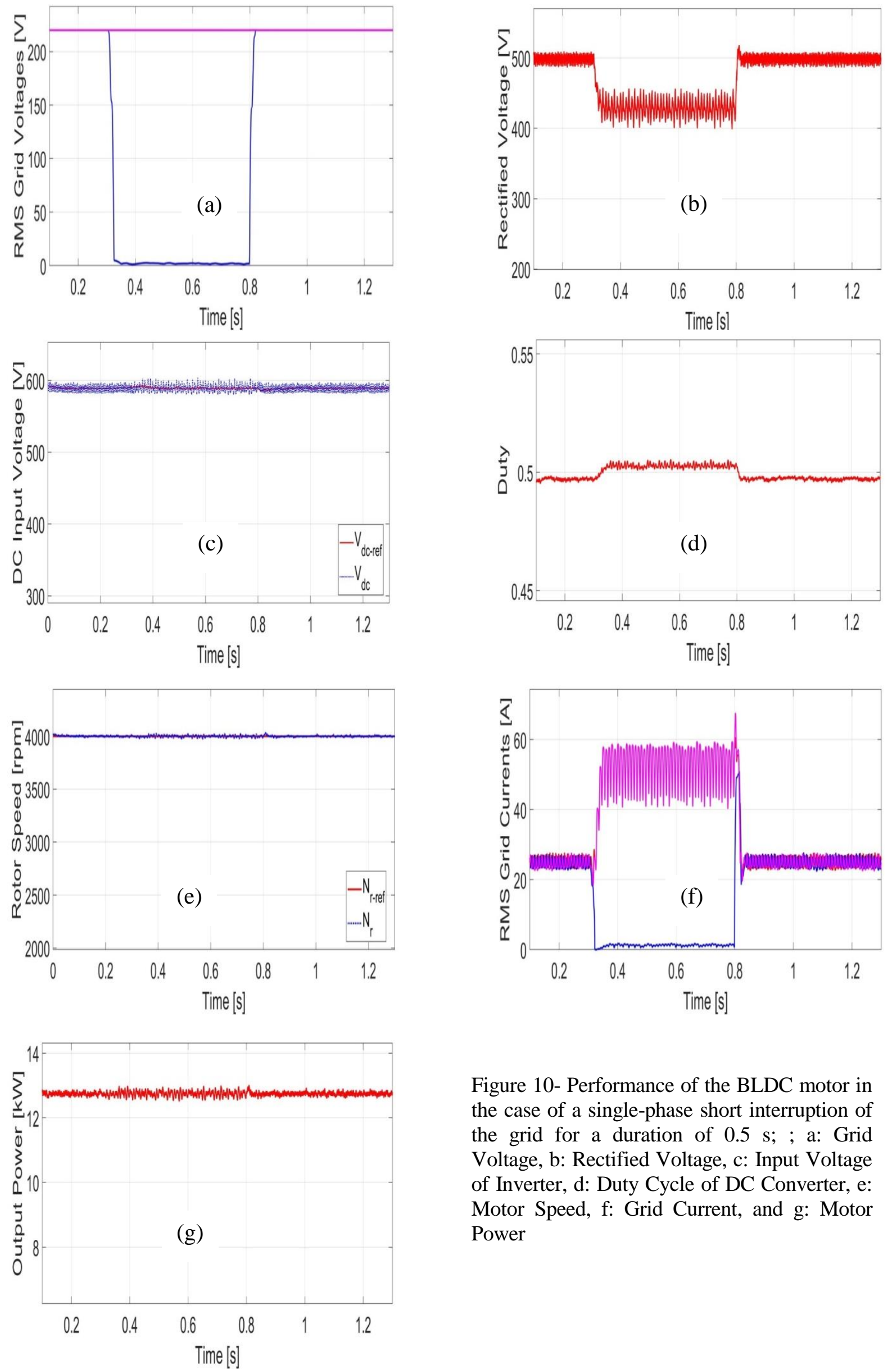

Figure 10- Performance of the BLDC motor in the case of a single-phase short interruption of the grid for a duration of $0.5 \mathrm{~s}$; ; a: Grid Voltage, b: Rectified Voltage, c: Input Voltage of Inverter, d: Duty Cycle of DC Converter, e: Motor Speed, f: Grid Current, and g: Motor Power 

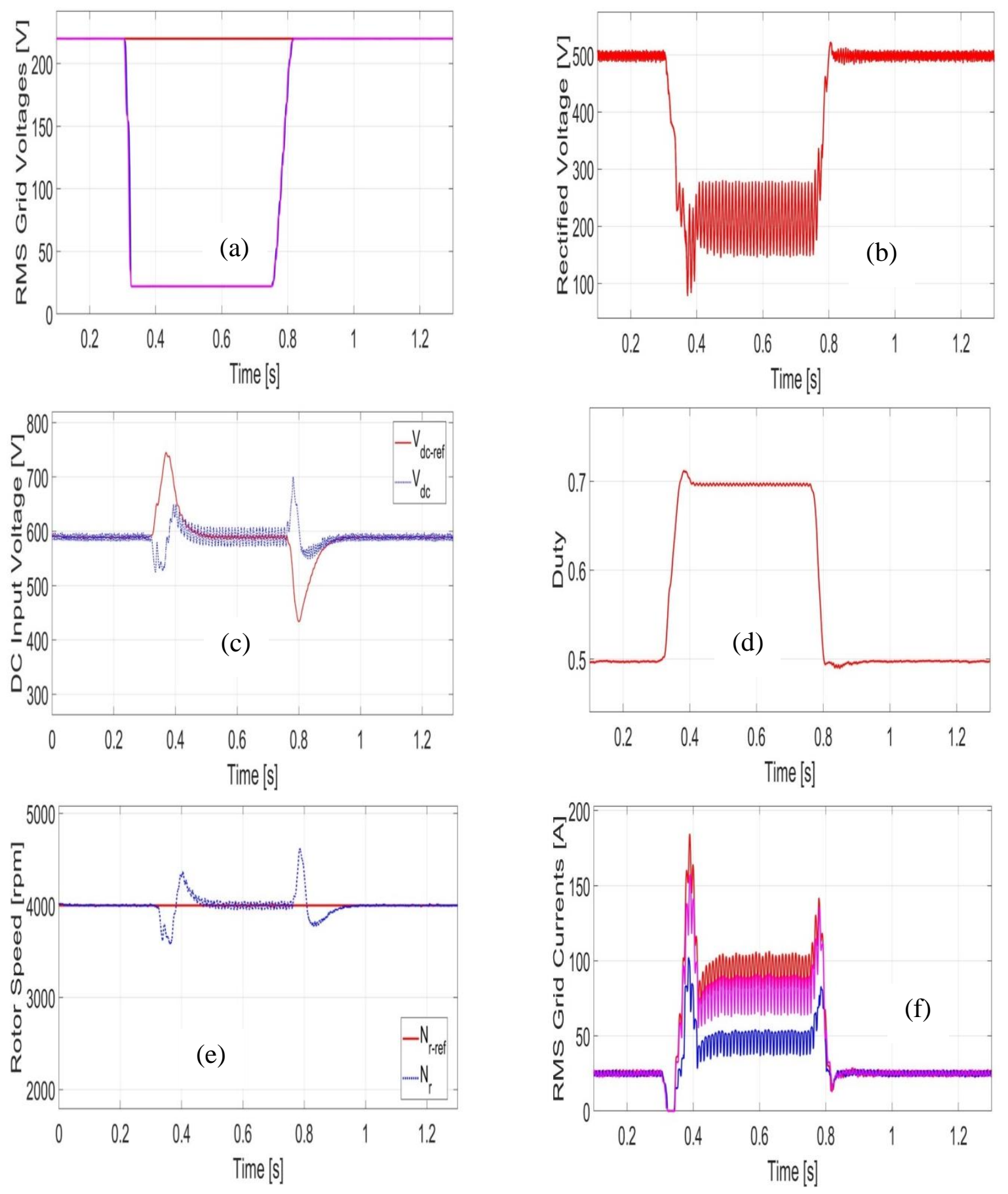

Figure 11- Performance of the BLDC motor in the case of a two-phase short interruption of the grid for a duration of $0.5 \mathrm{~s}$; a: Grid Voltage, b: Rectified Voltage, c: Input Voltage of Inverter, d: Duty Cycle of DC Converter, e: Motor Speed, f: Grid Current, and g: Motor Power

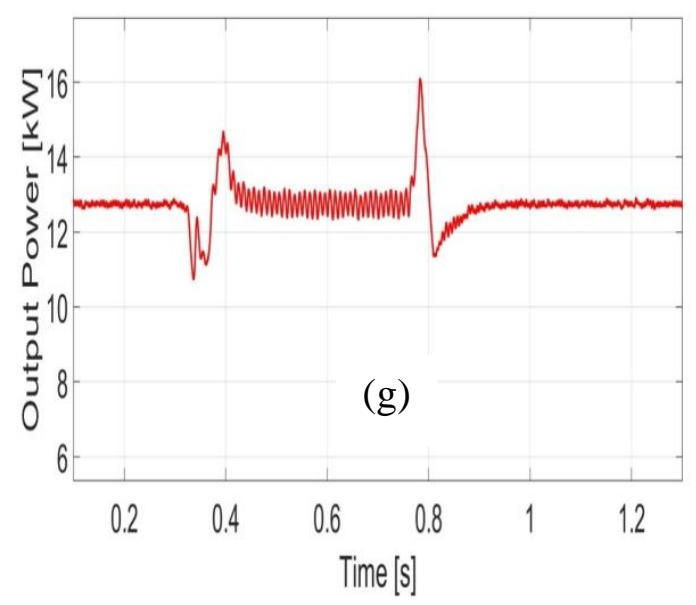




\section{Conclusions}

This paper has investigated the operation and control of the BLDC motor under various disturbance conditions such as voltage dips, swells, and short interruptions. To control the performance of the motor, a buck-boost converter is exploited. The converter is controlled by a two-loop cascade PI-controllers: outer loop for the speed control and inner loop for the dc voltage control. The Ant Colony Optimization technique has been implemented to tune the gains of the PI controllers to obtain the desired transient and steady-state responses. The operation of the motor and the controllers was tested via extensive simulation in MATLAB/SIMULINK with balanced and unbalanced grid disturbances. The simulation results proved that the designed controllers can compensate the motor and restore its speed and torque to the desired values with the desired response. The proposed configuration with the optimized controller proved to be one of the possible solutions to increase the ride-through capability of the BLDC motor against major power quality problems. However, more research work is needed to explore other options.

\section{References}

[1] Edward C. Lee, "Brushless DC: a modern approach to variable speed drives", IEEE Ind. Applications Society Annual Meeting Seattle, WA, USA, 7-12 Oct. 1990, pp. 14841488.

[2] T.M. Jahns, "Motion control with permanentmagnet AC machines", Proceedings of the IEEE, Aug 1994, Vol. 82, Issue: 8, pp.: 1241 1252.

[3] T.J.E Miller, T.J.E Rabinovici, "Back-emf waveforms and core losses in brushless dc motors". IEEE Proceeding on Electronic Power Applications, May .1994, Vol.141, Issue: 3, pp. 144 - 154

[4] Ramu Krishnan, Permanent magnet synchronous and brushless dc motor drives, Textbook, CRC Press, U.S.A, September 25, 2009, ISBN 9780824753849.

[5] D. Lee, "Development of BLDC motor and multi-blade fan for HEV battery cooling system", International Journal of Automotive Technology, Springer, Electronic ISSN, 19763832, vol. 15, no. 7, pp. 1101-1106, 2014. Available: 10.1007/s12239-014-0114-7.

[6] Dirk Leman, "Green Combustion Cars Drive on Electric (BLDC) Motors", Advanced Microsystems for Automotive Applications 2010, Springer, Online ISSN, 978-3-64216362-3 pp 13-20.

[7] Rini Nur Hasanah, Victor Andrean, Soeprapto, Hadi Suyono; R. Arief Setyawan, "Bidirectional VSI as a regenerative-braking converter for BLDC motor - An analysis on a plug-in electric vehicle application", the 10th International Conference on Electrical and Electronics Engineering (ELECO), Bursa, Turkey, 30 Nov.-2 Dec 2017, pp. 222 - 226.

[8] Tinu Francis and P. Gokulakrishnan, "Embedded Based PFC Converter for an Air Conditioner with BLDC Motor", Power Electronics and Renewable Energy Systems, Lecture Notes in Electrical Engineering 326, Chapter 62, pp. 631-641, Springer, New Delhi.

[9] Volkhard Führer, Alexander Reul, "Modular Electric Oil Pumps with BLDC Motors", The ATZ worldwide Journal, Springer, 2015, Issue 12, pp. 26-31.

[10] P. Santhosh and P. Vijayakumar, "Performance Study of BLDC Motor Used in Wireless Medical Applications", Wireless Personal Communications: An International Journal, Springer, Electronic ISSN, 1572834X, Vol. 94 Issue 4, June 2017, pp. 24512458

[11] Kadwane, Sumant G., Kumbhare, Jyoti M., Gawande, S. P. and Mohanta, D. K, "Reliability evaluation of BLDC drive in refrigeration systems", The 42nd Annual Conference of the IEEE Industrial Electronics Society IECON, 23-26 October 2016, Florence, Italy, pp.6645-6650.

[12] D Kamalakannan, N Jeyapaul Singh, M Karthi, V Narayanan and N S Ramanathan, "Design and development of DC powered BLDC motor for Mixer-Grinder application", The IEEE First International Conference on Sustainable Green Buildings and Communities (SGBC), Chennai, India, 18-20 Dec., 2016, pp. 1-6.

[13] S Veeraraghavan, M Kumaravel, Krishna Vasudevan and Ashok Jhunjhunwala, "Experimental studies and performance evaluation of solar PV powered BLDC motor drive with an integrated MPPT in fan applications", The IEEE 40th Photovoltaic Specialists Conference (PVSC) - Denver, CO, USA, 8-13 June 2014, pp. 3713 - 3718

[14] Padmaraja Yedamale, "Brushless dc (bldc) motor fundamentals". AN885 Microchip Technology Inc, July .2003.

[15] A. Rubaai and P. Young, "Hardware/software implementation of fuzzy-neural-network selflearning control methods for brushless DC motor drives," IEEE Transactions on Industry Applications, vol. 52, no. 1, pp. 414-424, 2016.

[16] W. Chen, Y. Liu, X. Li et al., "A novel method of reducing commutation torque ripple for brushless DC motor based on Cuk converter," IEEE Transactions on Power 
Electronics, vol. 32, no. 7, pp. 5497-5508, 2017.

[17] C. Kiree, D. Kumpanya, S. Tunyasrirut, and D. Puangdownreong, "PSO-based optimal PI(D) controller design for brushless DC motor speed control with back EMF detection," Journal of Electrical Engineering and Technology, Korean Institute of Electrical Engineers, vol. 11, no. 3, pp. 715-723, 2016, Available: 10.5370/jeet.2016.11.3.715.

[18] A. Sabir and M. Kassas, "A novel and simple hybrid fuzzy/PI controller for brushless DC motor drives," Automatika, Journal for Control, Measurement, Electronics, Computing and Communications, Taylor \& Francis, Online ISSN, 1848-3380, vol. 56, no. 4, pp. 424-435, 2015.

[19] C. Yu Jin, K. H. Ryu, S. W. Sung et al., "PID auto-tuning using new model reduction method and explicit PID tuning rule for a fractional order plus time delay model," Journal of Process Control, Elsevier, Online ISSN, 0959-1524, vol. 24, no. 1, pp. 113-128, 2014.

[20] D. Puangdownreong, A. Nawikavatan and C. Thammarat, "Optimal Design of I-PD Controller for DC Motor Speed Control System by Cuckoo Search", Procedia Computer Science, Elsevier, Online ISSN, 1877-0509, vol. 86, pp. 83-86, 2016. Available: 10.1016/j.procs.2016.05.021.

[21] K. J. ' Astr"om and T. H"agglund, "The future of PID control," Control Engineering Practice, Elsevier, Online ISSN, 0967-0661, vol. 9, no. 11, pp. 1163-1175, 2001.

[22] H. Ibrahim, F. Hassan, and A. O. Shomer, "Optimal PID control of a brushless DC motor using PSO and BF techniques," Ain Shams Eng. Journal, vol. 5, pp. 391-398, 2014.

[23] K. Premkumar and B. Manikandan, "Fuzzy PID supervised online ANFIS based speed controller for brushless dc motors," Neurocomputing, vol. 157, pp. 76-90, 2015.

[24] P. S. R. Nayak and T. A. Rufzal, "Flower Pollination Algorithm Based PI Controller Design for Induction Motor Scheme of SoftStarting," in the Proceedings of the 2018, 20th National Power Systems Conference (NPSC), Tiruchirappalli, India, 2018, pp. 1-6.

[25] E. Ali, "Speed control of DC series motor supplied by photovoltaic system via firefly algorithm", Neural Computing and Applications, Springer, Electronic ISSN, 1433-3058, vol. 26, no. 6, pp. 1321-1332, 2014. Available: 10.1007/s00521-014-1796-5.

[26] W. Xie, J. Wang and H. Wang, "PI Controller of Speed Regulation of Brushless DC Motor Based on Particle Swarm Optimization Algorithm with Improved Inertia Weights", Mathematical Problems in Engineering,
Hindawi, Online ISSN: 1563-5147, vol. 2019, pp. $1-12$, 2019. Available: $10.1155 / 2019 / 2671792$.

[27] M. Moghaddas, M. Dastranj, N. Changizi and M. Rouhani, "PID Control of DC Motor Using Particle Swarm Optimization (PSO) Algorithm", Journal of Mathematics and Computer Science, International Scientific Research Publications MY SDN. BHD, vol. 01, no. 04, pp. 386-391, 2010. Available: 10.22436/jmcs.001.04.16.

[28] B. Adhavan, A. Kuppuswamy, G. Jayabaskaran and V. Jagannathan, "Field oriented control of Permanent Magnet Synchronous Motor (PMSM) using fuzzy logic controller," in the Proceeding of 2011 IEEE Recent Advances in Intelligent Computational Systems, Trivandrum, Kerala, 2011, pp. 587-592.

[29] B. Sarkar, P. Mandal, R. Saha, S. Mookherjee and D. Sanyal, "GA-optimized feedforwardPID tracking control for a rugged electrohydraulic system design", ISA Transactions, Elsevier ISSN, 0019-0578, vol. 52, no. 6, pp. 853-861, 2013. Available: 10.1016/j.isatra.2013.07.008.

[30] G. Zeng et al., "Design of multivariable PID controllers using real-coded population-based extremal optimization", Neurocomputing, Elsevier, ISSN, 0925-2312, vol. 151, pp. 1343-1353, 2015.2 Available: 10.1016/j.neucom.2014.10.060.

[31] J. Zhang and S. Yang, "An incremental-PIDcontrolled particle swarm optimization algorithm for EEG-data-based estimation of operator functional state", Biomedical Signal Processing and Control, Elsevier ISSN, 17468094,vol. 14, pp. 272-284, 2014. Available: 10.1016/j.bspc.2014.08.005.

[32] T. Kumbasar and H. Hagras, "Big Bang-Big Crunch optimization based interval type-2 fuzzy PID cascade controller design strategy", Information Sciences, Elsevier ISSN, 00200255, vol. 282, pp. 277-295, 2014. Available: 10.1016/j.ins.2014.06.005..

[33] A. Rajasekhara, R. K. Jatothb, A. Abrahamcd, "Design of intelligent PID/PI $\lambda \mathrm{D} \mu$ speed controller for chopper fed DC motor drive using opposition based artificial bee colony algorithm", Engineering Applications of Artificial Intelligence, Elsevier, ISSN, 09521976, Vol. 29, March 2014, pp. 13-32. https://doi.org/10.1016/j.engappai.2013.12.00 9.

[34] S. A. Taher, M. Hajiakbari Fini, and S. Falahati Aliabadi, "Fractional order PID controller design for LFC in electric power systems using imperialist competitive algorithm," Ain Shams Engineering Journal, 
ISSN, 2090-4479, vol. 5, no. 1, pp. 121-135, 2014.

[35] R. K. Sahu, S. Panda, and U. K. Rout, "DE optimized parallel 2- DOF PID controller for load frequency control of power system with governor dead-band nonlinearity," International Journal of Electrical Power \&Energy Systems, Elsevier, ISSN 0142-0615, vol. 49, no. 1, pp. 19-33, 2013.

[36] F. Cao and W. Wang, "Harmony search-based particle swarm optimization approach for optimal PID control in electroslag remelting process," International Journal of Modelling, Identification and Control, Inderscience , ISSN, 1746-6180,vol. 15, no. 1, pp. 20-27, 2012.

[37] Dorigo, M., Maniezzo, V., and Colorni, A., "Positive Feedback as a Search Strategy," Technical report 91-016, Dipartimento di Elettronica, Politecnico di Milano, Italy, 1991.

[38] Dorigo, M., "Optimization, Learning and Natural Algorithms" Ph.D. thesis, Dipartimento di Elettronica, Politecnico di Milano, 1992 (in Italian).

[39] Shengqiang Li, Xiaodong Liang and W. Xu, "Modeling DC motor drive systems in power system dynamic studies," 2014 IEEE/IAS 50th Industrial \& Commercial Power Systems Technical Conference, Fort Worth, TX, 2014, pp. 1-11, doi: 10.1109/ICPS.2014.6839167.[40] E. R. Collins and A. Mansoor, "Effects of voltage sags on AC motor drives," 1997 IEEE Annual Textile, Fiber and Film Industry Technical Conference, Greenville, SC, USA, 1997, pp. 9. 7 pp.-, 10.1109/TEXCON.1997.598533.

[41] Myo Thu Aung and J. V. Milanovic, "Analytical assessment of the effects of voltage sags on induction motor dynamic responses," 2005 IEEE Russia Power Tech, St. Petersburg, 2005, pp. 1-7, doi: 10.1109/PTC.2005.4524363.

[42] A. K. Goswami, C. P. Gupta and G. K. Singh, "Voltage Sag Assessment in a Large Chemical Industry," 2008 Joint International Conference on Power System Technology and IEEE Power India Conference, New Delhi, 2008, pp. 1-7, doi: 10.1109/ICPST.2008.4745220.

[43] N. Edomah, "Effects of voltage sags, swell and other disturbances on electrical equipment and their economic implications," CIRED 2009 20th International Conference and Exhibition on Electricity Distribution - Part 1, Prague, Czech Republic, 2009, pp. 1-4, doi: 10.1049/cp.2009.0502.

[44] J. C. Gomez, M. M. Morcos, C. A. Reineri and G. N. Campetelli, "Behaviour of induction motor due to voltage sags and short interruptions," in IEEE Transactions on Power
Delivery, vol. 17, no. 2, pp. 434-440, April 2002, doi: 10.1109/61.997914.

[45] M.H.J. Bollen, Understanding Power Quality Problems: Voltage Sags and Interruptions, Textbook, New York, IEEE Press, Online ISBN: 9780470546840, 1999.

[46] R. C. Dugan, M. F. McGranaghan, H. W. Beaty, Electrical Power Systems Quality, Textbook, ISBN-10: 0071761551,New York, McGraw-Hill, 1996.

[47] European Standard EN 50160, "Voltage characteristics of electricity supplied by public distribution systems.", available at: https://copperalliance.org.uk/uploads/2018/03/ 542-standard-en-50160-voltagecharacteristics-in.pdf

[48] J. C. Das, "Effects of momentary voltage dips on the operation of induction and synchronous motors", IEEE Transactions on Industry Applications, 1990, Vol. 26, No. 4, pp. 711 718

[49] Ian Griffin, "On-line PID Controller Tuning using Genetic Algorithm", Master Thesis, Dublin City University, 2003

[50] H. Ying-Tung, C. Cheng-Long, C. ChengChih, "Ant Colony Optimization for Designing of PID Controllers", IEEE International Symposium on Computer Aided Control Systems Design, Taipei, Taiwan, 24th September, 2004.

[51] I. Chiha, P. Borne, "Multi-Objective Ant Colony Optimization to Tuning PID Controller", Proceedings of the International Journal of Engineering, Vol. III, issue no. 2, March 2010.

[52] B. Nagaraj and N. Murugananth, "A comparative study of PID controller tuning using GA, EP, PSO and ACO," 2010 International Conference on Communication Control and Computing Technologies, Ramanathapuram, 2010, pp. 305-313.

[53] F.Hassan, A.Wakeel, A.Kamel and A.Abdelhamed. "Optimum Tuning of PID Controller for a Permanent Magnet Brushless Motor", Proceedings of the 8th ICEENG Conference, 29-31 May 2012.

\section{Appendix: Motor Parameters}

Rated Power: $17 \mathrm{hp}$

Rated Speed: 4000 rpm

Rated Torque: $30 \mathrm{Nm}$

Stator phase resistance Rs: $0.7 \Omega$

Stator phase inductance Ls :2.72 $\mathrm{mH}$

Back EMF flat area: 1200

Inertia $0.8 \mathrm{~g} \cdot \mathrm{m} 2$

viscous damping: $1 \mathrm{mN} . \mathrm{m} . \mathrm{s}$

pole pairs: 4

Reference: https://www.miromax.lt/en/apie_mus 